\title{
Formation of Competence of a Specialist of Digital Economy
}

\author{
Khutornaya M.L.* \\ Voronezh State University of Engineering Technologies \\ Voronezh, Russia \\ e-mail: mlh10@yandex.ru
}

\author{
Zlobin A.N. \\ Voronezh State University of Engineering Technologies \\ Voronezh, Russia \\ e-mail: dronns@yandex.ru
}

\author{
Kurchenkov A.A. \\ Voronezh State University of Engineering Technologies \\ Voronezh, Russia \\ e-mail: kurwol1952@yandex.ru
}

\begin{abstract}
The subject of the study is the invariants of professionalism needed by a specialist in the digital economy: self-awareness and stress tolerance. The incredible increase in the volume of information, the course of social processes in society, the state of the economy increases the requirements for a specialist, modeling all his competencies as a source of innovation, dictating the need for self-development, selfrealization, i.e., readiness for activity, for life in a globalizing world. The authors examine the competency-based approach to education, the main trends and requirements for a specialist in the digital economy. The most important feature of modern education is highlighted: improvement in the educational space of the basic and special competencies of today's student and future specialist. The authors' definition of the concept of "selfawareness" is proposed. The personality determinants that are formed in the educational process are analyzed: responsibility, speed of thinking and decision-making, stress resistance, selfawareness, professional self-consciousness, formed in the educational space, and subsequently actively affecting the educational and organizational processes that determine their effectiveness, systematic coordination of many tasks, productivity. The historical path of the appearance of the phenomenon of self-awareness from antiquity to modernity is traced. The results of the questionnaire "Factors and conditions of stress resistance of first-year students" are proposed: psychological competence; anticipation of luck; features of the educational process; self-image; health situation; demotivation. Based on the identified factors, the internal psychological conditions for overcoming stress and increasing stress resistance are described. As a result of the work done, conclusions are drawn that the most important feature of modern education is the formation and improvement in the educational space of the basic and special competencies of today's student and future specialist in the digital economy: self-awareness and stress tolerance.
\end{abstract}

Keywords - digital economy, competence, personnel, selfawareness, professional self-awareness, stress tolerance, student.

\section{INTRODUCTION}

In modern socio-economic conditions, the personnel system symbolizes the fundamental link of personnel management and, in accordance with the current demand of the time, requires promising changes, the search for previously unknown competencies.

The components of competence have been studied for a long time by scientists of various disciplines. Russian authors, taking into account the mentality of the nation, the peculiarities of Russian organizational changes, and socioeconomic dynamics, mean in general terms the concept of competence as a set of abilities, qualities and personality traits necessary for successful professional activity in a particular field (V.A. Slastenin, Ivanov) [12].

I.P. Medintseva [3] suggests that the competency-based approach is identical to the holistic experience of solving life problems, performing professional and key functions, social roles, and competencies.

E.Ya. Kogan [4] believes that competence is a combination of personality characteristics and exogenous conditions conducive to its development and endowed with certain qualities:

1) the level of professional culture;

2) awareness of the motives of work;

3) cognitive search;

4) independence;

5) phonetic and syntactic literacy;

6) resource mobilization;

7) the desire for learning.

The whole set of qualities of a specialist listed above begins to take shape in the educational environment, and therefore in recent years the emphasis in education has been on practical orientation, on a competency-based approach.

\section{LITERATURE REVIEW}

But the development of various branches of the social institutions of modern Russian society presupposes a change in the system of higher education to fill the fields of science and technology with new generation professionals, capable of 
not only full-time work and high quality of life, but also innovative activity. Moreover, their activity should be innovative. Authors T.V. Sabetova, M.V. Ponomarenko point out that the innovative behavior of employees is formed under the influence of factors related to the characteristics of the management style; job characteristics and job responsibilities; associated with interpersonal and intergroup relationships, [5]. It can be added that this formation is carried out at the stage of study at the university, and future activities are inextricably linked with digitalization.

The beginning of the digital revolution with the advent of the Internet and lowering the cost of access to the global network has changed not only the economy, but also modern life in general.

In 2024, a program should be implemented on the comprehensive digital transformation of the economy and social sphere [6], since it was by this period that the goal of the reforms was set.

The tasks are as follows:

1) to develop legislation on digital technologies; modernize digital infrastructure;

2) provide digital practices for key areas of the economy;

$3)$ to prepare competent specialists for the digital field.

Since the directions of the Digital Economy of the Russian Federation program include normative regulation, the formation of research competencies and technical background, information infrastructure and information security, personnel and education, it is necessary to improve the higher education system, which should provide the digital economy with competent personnel.

Consider the main directions of the digital economy. For the qualitative development of the economy and social structures, a number of national projects have been created, one of which includes the development of the digital economy.

This direction has its pros and cons. The pros of the development of the digital economy include:

- increase in labor productivity;

- competitiveness of organizations;

- reduction of production costs;

- the emergence of new jobs;

- reduction of poverty and social inequality

But there are also disadvantages: this is the appearance of unemployment associated with the departure of a number of professions from the labor market. Therefore, the formation of a full-fledged digital environment implies the provision of highly qualified competent personnel for the digital economy.

According to the governing bodies, it is precisely the "digitalization" of the economy that will allow Russia to resolve the issue of global competitiveness and national security, which is why the requirements for invariants of professionalism are becoming quite stringent.
In the modern «world, the goal of education is to prepare a person for work in new conditions, which in recent years has integrated into the «Internet of People», «Internet of Things» (technical devices) «Internet of Services», «Internet of Everything» (INTERNET ALL)» [7, 8].

Qualitative composition of personnel may appear as a result of not reforms, but reformations. By reformation we mean (lat. Reformatio - correction, restoration) the change of values in higher education. The change in values entails the formation of certain personal determinants.

How can a future employee be presented, a user who has the necessary competencies for effective activities in the digital economy (including education, culture, research, defense and security), who in his work addresses the digital environment and digital tools as a student and professional?

A specialist in this field can not be guided by a narrow competency, as he must understand the exact sciences, programming, cognitive research, investment and management, and strategic management, which is based on the social well-being of employees, on forecasting changes in the external environment [9].

Therefore, the most important feature of modern education is the formation and improvement in the educational space of the basic and special competencies of today's student and future specialist.

The time of study at the university correlates with the personal, professional, social achievements of the staff.

Education should be comprehensively developing. And the acquisition of professional skills is complemented by the formation of a moral culture and values, legal literacy, and student mentality.

The possession of only information technologies, information modeling is not a complete range of competencies for the effective activity of a specialist and his competitiveness. The competencies of a professional are necessary and important, and they include: creative and critical thinking, independence and responsibility, psychological adaptation, innovativeness, enterprise, emotional intelligence, which is based on stress resistance, which will be discussed later.

Therefore, the faculty is faced with a rather serious psychological and pedagogical task: to teach the student the ability to plan, organize his activities, form a spectrum of thoughts, values that promote a civic position and at the same time lay the foundations of the student's thinking as a subject of educational activity, increasing motivation for learning.

Such a statement of the question implies the determination of an action vector aimed at the success of training, a phased program of implementation and a clear organization of the educational process.

The incredible increase in the volume of information, the course of social processes in society, the state of the economy increases the requirements for a specialist, modeling all his competencies as a source of innovation, dictating the need for self-development, self-realization, i.e. readiness for activity, for life in the context of globalization [10]. 
In that case, the transference of consciousness, selfconsciousness and the permanent process of formation of personal determinants in the learning process is completed by the acquisition of the qualities, which are necessary for a specialist in the digital economy: responsibility, quick thinking and decision making, stress resistance, self-awareness.

In addition, in the formation of a personality of a future professional, a significant role is played by professional selfawareness, arising in the educational space, and subsequently actively influencing educational and organizational processes, determining their effectiveness, systematic coordination of many tasks, and productivity.

Federal Law "On Education in the Russian Federation" N 273-FL dated December 29, 2012, which entered into force on September 1, 2013 in article No. 48 reads: "Duties and responsibilities of teachers:

1) "comply with legal, moral and ethical standards, follow the requirements of professional ethics";

2) 'to develop students' cognitive activity, independence, initiative, creative abilities, to form a civic position, the ability to work and live in the modern world, to form a healthy and safe lifestyle culture among students" [11].

Therefore, the tasks of university education include not only the formation of professional skills, but also the formation of professional self-awareness.

\section{Methodology}

In our opinion, self-awareness is an analytical introspection, due to personal values, moral beliefs and attitudes, self-identification, a behavioral component formed by social institutions, where the educational space plays an important role. At the same time, professional self-awareness also includes volitional components: independence, responsibility, discipline, the desire for "acme" $[12,13]$. Consider the history of the concept of "self-awareness."

The history of science is connected in ancient time, in which a cosmocentric worldview prevailed, where the phenomena and events of the surrounding world were explained by the influence and power of the cosmos, while emphasis was placed on some connection between the mind and the object, which exist independently of each other [14].

The connection between the cosmos and man was carried out through the consciousness of man. Augustine Aurelius the Blessed first spoke about self-awareness in the 5th century. Since then, the reflective side of consciousness has been given special attention. In modern times, the idea of renouncing God gave rise to a number of ideas of rational constructions, and one of them was about the only undoubted reality that the individual and his consciousness were recognized. The concept of "consciousness" is equated with the concept of "thinking." In the process of self-consciousness, consciousness knows its place and clarifies its structure. In philosophy, the problem of self-consciousness is most fully represented in German classics, and it is defined as a philosophy of selfconsciousness. The main thesis of this philosophy: there is no consciousness without self-awareness.
By the middle of the 19th century, social preconditions for revising the new European metaphor of consciousness had developed. K. Marx formulated the idea of the secondary nature of consciousness, its dependence by factors exogenous to it, and above all, economic.

In the Dahl dictionary, consciousness is defined primarily as "self-consciousness," the memory of oneself.

In the modern scientific world of philosophy, psychology and sociology, the problem of consciousness and selfconsciousness is one of the topics discussed today.

Self-awareness can be characterized as an individual ideology, a subjective attitude to one's motives, needs, and strong-willed components. According to A.A. Derkach, selfawareness (self-image) is a systematized representation of a person about himself, about his physical, intellectual, strongwilled, emotional, characterological and other features [15].

Self-awareness can not be a finished one-day process, it is formed in the process of communication and activity, is a derivative of the subjectivity of a person. The student period is associated with such new aspects in the life of a person as professional self-awareness.

The origin and development of this concept is associated with professional skill (M.I. Zhukova, A. G. Vasyuk, E.M. Borisova), with the degree of professional training (V.V. Ovsyannikova, G. Rainay, N.O. Tkacheva), with the professional development of the subject as a whole (E.A. Klimov, V.N. Koziev, S.V. Vaskovskaya).

Scientists suggest that professional identity correlates with the concepts of "professional activity", "subject of this activity." Therefore, there are differences from the concept of "self-awareness," which puts a greater emphasis on the basic structural determinants: self-acceptance, self-expression, selfesteem, self-acceptance and self-attitude. Professional selfawareness is the projection of all the structural components of self-awareness onto professional activities.

Professional self-awareness is a complex personal array that is formed under the influence of the professional environment, in particular, the educational process at the university, socio-economic changes, including a person's awareness of such elements as: the characteristics of his profession;

1) the presence of paramount professional qualities;

2) development opportunities;

3) the exclusion of emotional burnout;

4) assessment of oneself as a professional by colleagues;

5) understanding of their professional behavior and, if necessary, the possibility of its correction.

The development of professional reflection leads to the improvement of conscious attitudes of a personality, a new professional position, and a change in professional and personal characteristics.

The educational environment that should help the future specialist adapt to digital transformation. 


\section{ASSESSMENT METHODOLOGY}

Digital transformation is not just the evolution of devices: it is the co-evolution of smart data arrays in all areas of life. Digitalization is replacing traditional paradigms with new models. The object and subject of digitalization is not only organizational and work processes, but also management processes, personal information, social and psychological processes. The digital ecosystem affects almost all spheres of human life, even during sleep.

Such a large-scale globalization cannot but affect the invariants of professionalism, in particular, stress resistance. Therefore, there is a need to study the relationship of professional identity and its component of stress tolerance.

Stress tolerance is one of the invariants of professionalism, including, in our opinion, not only cognitive, emotional and psychophysiological characteristics, but some kind of "training" of the psyche that has formed during the study. Therefore, the ability to stress-free respond to intellectual tests, work with a temporary perspective, and show social activity in the form of an active position of the person in goalsetting and goal-realization; realize responsibility for the results of operations; the ability to proactively, critically and innovatively reflect and anticipate the results of activities and relationships - all this allows not only to successfully master the profession, but also to become a competitive specialist in the world of digital economy.

In order to study the factors for identifying stress resistance in educational activities, we compiled a questionnaire "Factors and conditions of stress resistance of first-year students." The respondents were first-year students of the Faculty of Technology of the Voronezh State University of Engineering Technologies in the amount of 75 people. Gender differences were not taken into account. Statistical data processing and Varimax rotation highlighted the following factors:

\section{Psychological competence;}

2. The anticipation of luck;

3. Features of the educational process;

\section{I-image;}

5. The health situation;

\section{Demotivation}

The first factor "psychological competence" with a significant weight load included the components "adaptation in the new team" (0.765), "position in the student team" $(0.749)$, "satisfaction with the professional choice made" (0.689), "novelty of the training system" $(0.583)$ and other similar manifestations were grouped into this factor, since they meant situational anxiety of the student's personality and contained signs of impaired activity.

The second factor "anticipation of luck" included "leadership qualities" (0.825), "satisfaction with one's answers" (0.733), "worries about the time perspective" (0.519), and others. Anticipation of luck before its onset increased stress tolerance of the situation.
The third factor "features of the educational process" with a significant weight load included the components "selfawareness and self-acceptance" (0.788), "participation in the preparation of interactive classes" (0.768), "positive subjectsubject relations" $(0.745)$, and "professional reflection" (0.680), etc. Similar manifestations were grouped into this factor, since they meant the motivation of the student's personality, contained signs of active educational activity and the formation of professional self-awareness.

"I-image" was the content of the fourth factor. It included "motivation" (0.784), "planning of educational activities" $(0.775)$, "active independent work" $(0.688)$, "level of personal self-regulation" (0.655), "possession of psycho-regulatory technologies of behavior" (0.546); "Communicative skills" (0.546), etc.

The "health situation" was naturally singled out as the fifth factor, which reduced personal potential and stress resistance. This factor included such components as "headache and somatic pain" (0.813), "overwork" (0.724), "insomnia" (0.675), "climate change" (0.523), "homesickness" (0.478), etc.

The components of the following sixth factor "demotivation" were "unreasonable judgments about one's own problems in knowledge" $(0.763)$, "applying an outdated learning system" (0.756), "lack of interest in the subjects studied" (0.641), "fear of active actions" (0.614), "Claims to their own logical reasoning" (0.579), etc.

Thus, factors are highlighted, of which the fifth and sixth were negative.

\section{ANALYSIS}

The identified factors were psychological in nature and quite fully described the students' stress tolerance.

Based on the identified factors, we can distinguish internal psychological conditions for overcoming stress and increasing stress resistance:

1. The formation of professional identity in the process of educational activity;

\section{Introspection and reflection;}

3. Personal representation in the educational process;

4. The allocation of the subjective basis for an optimistic forecast;

5. Strategic goal setting;

6. Planning for independence in scientific research;

7. Proactive failure warning;

8. The formation of the level of personal self-regulation;

9. The correct distribution of psychoenergetic resources;

10. Improving communication skills and adaptive mechanisms.

Since stress resistance is a component of professional selfawareness, the formation of professional self-awareness is a 
priority in the learning process. The main criterion of readiness for a certain professional activity is its presence. The content of professional consciousness includes a set of conscious professionally necessary generalized and operational knowledge about the goals, means, plans of professional activity, about the subjects and subject of professional interaction, about the parameters, norms for assessing the effectiveness of professional activity.

Effectively form a professional orientation of consciousness allows self-awareness by a specialist, it also helps to understand the motivation for professional activity and determine the value, necessity and importance of future profession.

The features of professional consciousness, the existence in it of certain groups of elements depends on the content of professional activity within the framework of a particular profession. However, the professional consciousness of representatives of a particular profession includes a number of common components related to the nature of their professional activities.

The following components are characteristic of professional consciousness: psychological component, epistemological component, practice-oriented component, axiological component, emotional-volitional component, psychophysiological.

In our opinion, the professional identity of a digital economy specialist includes the following elements:

1) the assimilation of the requirements for the personality in the profession;

2) building interpersonal relationships in professional activities;

3) understanding of the responsibility of one's professional role and responsibilities in relation to society as a whole;

4) criticality in relation to the acquired competencies in this profession;

5) the desire, if necessary, for additional training and development;

6) self-regulation and ergonomic consumption of psychoenergy resources;

7) analysis of their personal capabilities with specific professional requirements.

Thus, professional self-awareness is a component of consciousness, includes not only cognitive, but also emotional-volitional components, in particular, stress tolerance, and involves the reflective contribution of the personality to the process of introspection. The main function of the professional consciousness of the individual is the constant regulation of professional activity.

\section{DISCUSSION}

The results of the work allow highlighting the direction of the vector of further scientific and practical search for a solution to the problem of studying and developing the competencies of a digital technology specialist in the educational space. It can be aimed at:

1) the formation of professional self-awareness and stress resistance;

2) the organization of experimental research to identify motivational, intellectual, emotional, volitional determinants of personality in the framework of the problem under study;

3) development of a psychological-acmeological model for the formation of basic and special student competencies, including the use of innovative technologies (design and research technology, developmental learning technology, problem-based learning technology, moderation technology, case-methods, intelligence-card technologies, inventive problem solving technologies; technologies for the development of critical thinking), interactive teaching methods, taking into account the psycho-physiological characteristics;

4) the organization of individual training plans with the involvement of students in scientific research and practical work;

5) the development and provision of methodological material for the independent work of students and assignments involving non-standard solutions.

\section{CONCLUSION}

Thus, to ensure the success and competitiveness of young people in the labor market, it is necessary to gradually build professional self-awareness in the process of training at a university. Using the principle of stimulating and motivating a positive attitude of students, it is possible to establish a logical connection between the success of their cognitive activity and the awakening of interest in it. Therefore, the educational environment is a platform for starting a professional with the necessary competencies. The use of the capabilities of modern information and communication technologies in the selection of individual labor trajectories and a professional route will be relevant.

The subject of further research may be the phenomenon of motivation in educational activities, as the fundamental dominant for the formation of professional invariants in digital space.

\section{References}

[1] V.A. Slastenin, Pedagogy. Textbook allowance for students. higher ped textbook. Institutions. Moscow: Publ. Center “Academy”, 2002, 576 p.

[2] D.A. Ivanov, Competency-based approach in education- Problems, concepts, tools. Educational - methodical manual. Moscow: APKiPRO, 2003, $101 \mathrm{p}$

[3] I.P. Medintseva, Competency-based approach in education, [Pedagogical excellence: materials of the II Intern. scientific conf.]. Moscow: Buki Vedi, April, 2012.

[4] E.Ya. Kogan, Competency-based approach and a new quality of education. Samara: Pros, 2001, 238 p.

[5] T.V. Sabetova, M.V. Ponomarenko, "Analysis and ranging of the factors of formation and development of innovative behaviour in organizations", Proc. of the Voronezh State Univer. of Engineer. 
Technol., vol. 80, no. 3, pp. 478-488, 2018. Retrieved from: https://doi.org/10.20914/2310-1202-2018-3-478-488

[6] Program "Digital Economy of the Russian Federation": Order of the Government of the Russian Federation of 28 July 2017, no. 1632-p.

[7] V.V. Lukin, Education. Technology. Economy, Monograph. Moscow: Ed. and Inform., 2018, 112 p.

[8] I.A. Kiseleva, N.E. Simonovich, E.D. Solomatina, "Social well-being of people and the strategy of innovative development of the enterprise", Proc. of the Voronezh State Univer. of Engineer. Technol., vol. 81, no. 1, pp. 402-411, 2019. Retrieved from: https://doi.org/10.20914/2310-1202-2019-1-402-411

[9] V.N. Knyazev, Social Management of the Labor Market: Encyclopedia. Moscow: Publ. house GUU, 2017, 679 p.
[10] Federal Law “On Education in the Russian Federation”, no. 273-Ф3 dated 29 December 2012. Retrieved from: http://www.consultant.ru/document/cons_doc_LAW_140174/

[11] M.L. Khutornaya, E.V. Barkalova, "Psychological analysis of the components of the concept of "worldview"”, Prospects for sci. and ed., no. 2, pp. 188-192, 2018.

[12] VV. Lukin, The unity of education and personnel policy as a tool for the development of a methodological system in the conditions information society. Moscow: Ed. and computer sci., 2002, 120 p.

[13] M.G. Yaroshevsky, "The history of psychology". Second revised edition. Moscow: Thought, 2012, 446 p.

[14] A.A. Derkach, Acmeological basis for the development of a professional. Moscow: Publ. house of the Moscow Psychol. and Soc. Instit. NPO MODEK, 2004, 400 p. 